\title{
Rho activation regulates CXCL12 chemokine stimulated actin rearrangement and restitution in model intestinal epithelia
}

\author{
Rebecca A Moyer ${ }^{1}$, Michael K Wendt ${ }^{1}$, Priscilla A Johanesen ${ }^{1}$, Jerrold R Turner ${ }^{2}$ and Michael B Dwinell ${ }^{1}$
}

Chemokines are critical regulatory factors that direct migration, proliferation and maturation of receptor expressing target cells within gut mucosa. The aim of the present study was to define the cellular mechanisms whereby engagement of the essential chemokine CXCL12 to CXCR4 regulates restitutive epithelial cell migration. Non-transformed IEC- 6 cells or polarized T84 epithelial monolayers were wounded and F-actin accumulation assessed using fluorescence microscopy and flow cytometry. Immunoblot analysis, pull-down assays, fluorescence microscopy and wound healing assays defined activation of Rho, Rho-kinase (ROCK), and myosin light chain (MLC) and the role for those Rho effectors in CXCL12regulated epithelial restitution. CXCL12 increased RhoGTP and F-actin localization to the leading edge of wounded IEC- 6 and T84 monolayers. CXCL12 congruently stimulated an increase in active MLC that was inhibited by blockade of ROCK and myosin light chain kinase and regulated epithelial migration. Our data in model intestinal epithelia suggest CXCR4 and CXCL12 may function as an autocrine and paracrine mucosal signaling network regulating the competency of the epithelial barrier to withstand injury and mediate repair following damage.

Laboratory Investigation (2007) 87, 807-817; doi:10.1038/labinvest.3700595; published online 18 June 2007

KEYWORDS: chemokines; epithelial cell migration; restitution; RhoGTPase; wound healing

The single layer of epithelial cells lining the gastrointestinal mucosal surface comprise a physical barrier between the external luminal environment and the internal milieu and are a critical component of the mucosal innate immune system. Defects in barrier integrity have been implicated in the etiology of inflammatory bowel disease, colorectal cancer, radiation injury, and infectious enterocolitis. Formation of an intact epithelium is tightly regulated and depends upon directed migration of epithelial cells out of the highly proliferative crypts of Leiberkühn ${ }^{1}$ and differentiation into mature enterocytes as those cells move up the crypt-villus axis. Sheet migration, typical of enterocytes within the mucosal epithelium, is also required for epithelial tissue repair. Intestinal wound repair is dependent upon the balance of three cellular events that include precise migration, proliferation, and differentiation of the epithelial cells adjacent to the wounded area. ${ }^{2,3}$ Intestinal epithelial cells, in contrast to leukocytes that move as single independent cells, migrate in a tight cohort with each other as intact epithelial sheets. ${ }^{4}$ The rapid, proliferation-independent migration of enterocytes across wounded mucosa is termed restitution. ${ }^{3}$

Directional trafficking of leukocytes is regulated by chemokines, host defense molecules that upon engagement to their G-protein coupled chemokine receptors regulate cellular migration and other processes required for epithelial wound repair. ${ }^{5}$ Chemokines can be subdivided into distinct inflammatory or homeostatic subsets, with the latter being minimally regulated by proinflammatory cytokine stimulation. ${ }^{5,6}$ We and others, ${ }^{7-10}$ have demonstrated the expression of several chemokine receptors, notably CXCR4, CCR5, CCR6, and $\mathrm{CX}_{3} \mathrm{CR} 1$, by human intestinal epithelial cells. Of these only CXCR4 is known to be embryonic lethal in genetically deficient knockout mice. ${ }^{11}$ Engagement of CXCR4 by its cognate ligand CXCL12 is known to be involved in proliferation of hematopoietic stem cells, migration of thymocytes, and inhibition of human immunodeficiency virus (HIV)-1 infection through occupancy of the chemokine co-receptor. ${ }^{12-14} \mathrm{~A}$ further role for CXCL12 engagement to CXCR4 has been established in the trafficking of multiple

\footnotetext{
'Department of Microbiology and Molecular Genetics, Medical College of Wisconsin, Milwaukee, WI, USA and ${ }^{2}$ Department of Pathology, University of Chicago, Chicago, IL, USA

Correspondence: Dr MB Dwinell, PhD, Department of Microbiology and Molecular Genetics, Medical College of Wisconsin, 8701 Watertown Plank Road, Milwaukee, WI 53226, USA. Email: mdwinell@mcw.edu
} 
metastatic carcinoma cells. ${ }^{15-23}$ The lethality phenotype exhibited by CXCR4 or CXCL12 gene deficient mice, while unique relative to chemokine receptors or chemokines, parallels the 'failure to thrive' and peri- and post-natal lethality observed in other genes encoding mediators of the innate immune system. ${ }^{24-27}$ Our laboratory has been investigating the role for this essential chemokine receptor-chemokine ligand signaling arc within the gastrointestinal mucosal immune system which rests critically upon a strong innate immune response to maintain overall health. ${ }^{6,7,20,28}$

The current paradigm asserts that chemokines upregulated in inflammation induce or exacerbate mucosal damage through the directed migration of infiltrating leukocytes expressing chemokine receptors such as CCR5 to the site of injury. ${ }^{29-36}$ In contrast, roles for those constitutively expressed chemokines and chemokine receptors such as CXCL12 and CXCR4 that are minimally regulated in inflammatory diseases remain largely unknown. In the present study, we tested the hypothesis that the chemokine receptor CXCR4 and its cognate ligand CXCL12 regulate epithelial wound healing through activation of a canonical wound healing pathway. ${ }^{37-44}$ Our findings are consistent with the notion that differing subsets of chemokines may not only exacerbate tissue injury through migration of leukocytes, but may also play a key role in the restitutive repair processes of mucosal inflammation.

\section{MATERIALS AND METHODS Materials}

Recombinant human CXCL12 was purchased from R\&D Systems (Minneapolis, MN, USA). The Rho kinase (ROCK) inhibitor Y27632 $\left(K_{\mathrm{i}}=140 \mathrm{mM}\right)$ was purchased from EMD Calbiochem (San Diego, CA, USA). The specific myosin light chain kinase (MLCK) inhibitor Drev-PIK was as described previously. ${ }^{45}$ The CXCR4 antagonist AMD3100 and lysophosphatidic acid (LPA) were purchased from Sigma (St Louis, MO, USA). Alexafluor-488-phalloidin and Alexafluor568 phalloidin were obtained from Invitrogen (Carlsbad, CA, USA). Antibodies for phospho-myosin light chain (MLC) and total-MLC were obtained from Cell Signaling Technologies (Danvers, MA, USA). Polyclonal rabbit antibody to CXCR4 was purchased from EMD Calbiochem and polyclonal actin antibody was obtained from Santa Cruz Biotechnology (Santa Cruz, CA, USA). Wild type and dominantactive Rho-GFP constructs were the kind gift from Dr Joseph Barbieri (Medical College of Wisconsin, Milwaukee, WI, USA). The dominant-negative Rho-GFP construct was constructed by substituting amino acid 19 of a wild-type RhoGFP plasmid construct to asparagine using the QuikChange II site-directed mutagenesis kit (Stratagene, La Jolla, CA, USA) according to the manufacturer's instructions.

\section{Cell Culture}

The normal, non-transformed rat small intestinal (IEC-6) cell line (CRL-1592) was purchased from the American Type
Culture Collection (ATCC; Rockvillle, MD, USA) and cultured using DMEM (4 g/l glucose), supplemented with 10\% $(\mathrm{v} / \mathrm{v})$ heat-inactivated fetal bovine serum (Omega Scientific, Tarzana, CA, USA), $2 \mathrm{mM}$ L-glutamine, $1.5 \mathrm{~g} / 1 \mathrm{NaHCO}_{3}$ and $0.1 \mathrm{U} / \mathrm{ml}$ bovine insulin (Invitrogen). The human T84 colonic carcinoma cell line ${ }^{46}$ was cultured in DMEM/Ham's F-12 medium [1:1] supplemented with 5\% (v/v) newborn calf serum (Invitrogen) and $2 \mathrm{mM} \mathrm{L}$-glutamine as described previously. ${ }^{6,28}$

\section{Reverse Transcriptase-PCR Analysis}

Total RNA was isolated from colonic crypt epithelium using TRIzol reagent (Invitrogen), DNase-treated (Ambion, Austin, TX, USA) and $2 \mu \mathrm{g}$ of total RNA was converted into cDNA via reverse transcription using random priming in a $40 \mu \mathrm{l}$ volume. CXCL12, CXCR4, glyceraldehyde-3-phosphate dehydrogenase (GAPDH), CD45 and villin mRNA transcripts were amplified using previously described PCR primers and conditions. ${ }^{20,28}$ As a negative control RNA was excluded in cDNA synthesis reactions, and as a separate control, template was excluded from the PCR.

\section{IEC-6 Wounding Assay}

Confluent IEC-6 cell monolayers grown in $60-\mathrm{mm}$ dishes were incubated $48 \mathrm{~h}$ in serum-free medium, wounded with a sterile razor blade and incubated with serum-free medium alone or $20 \mathrm{ng} / \mathrm{ml} \mathrm{CXCL12} \mathrm{for} 18 \mathrm{~h}$ at $37^{\circ} \mathrm{C}$ in $5 \% \mathrm{CO}_{2}$ as described previously. ${ }^{28,47,48}$ This dose of chemokine was selected as we have previously shown it to be optimal for both leukocyte chemotaxis and enterocyte migration. ${ }^{28}$ To assess CXCL12 signaling mechanisms, monolayers were pretreated for 30 min with Y27632 $(10 \mu \mathrm{M})$ or Drev-PIK $(300 \mu \mathrm{M})$ and stimulated in the presence or absence of CXCL12. Photomicrographs were taken using $\times 100$ magnification at $4-5$ locations per wound and the number of migrated cells determined by counting nucleated cells that crossed the wound edge. To assess F-actin accumulation, the wounded monolayers were stained with Alexafluor-488-phalloidin according to the manufacturer's instructions and imaged using a fluorescence microscope at $\times 200$ magnification.

\section{T84 Wounding Assay}

Polarized T84 cells were grown to confluence in six-well Transwell inserts (pore size $0.4 \mu \mathrm{m}$ Corning, Danvers, MA, USA) until transepithelial resistance (TER) was $\geq 1000 \Omega \mathrm{cm}^{2}$ as measured using a hand-held Millicell-ERS volt ohmmeter (Millipore). Cells were serum-starved $48 \mathrm{~h}$ and wounded with a $0.1-10 \mu$ l plastic pipette tip (USA Scientific, Ocala, FL, USA) connected to a bench top vacuum aspirator. In our hands, this apparatus consistently established round wounds of between 800 and $1000 \mu \mathrm{m}$ in diameter. Medium on wounded T84 monolayers was replaced with serum-free medium, or serum-free medium containing $20 \mathrm{ng} / \mathrm{ml}$ CXCL12. Photomicrographs were taken of the circular wounds using the $\times 4$ objective after wounding and each day 
thereafter and the area of each wound defined using Metamorph software. Barrier integrity of the same wounded monolayers was monitored using the hand-held Millicell-ERS volt-ohmmeter to measure TER of the injured and restitutive T84 epithelium.

\section{Rho Activation Assay}

RhoGTP levels were assessed using a Rho-binding domain (RBD) affinity precipitation assay (Cytoskeleton, Denver, CO, USA). ${ }^{49}$ Briefly, IEC-6 cells were grown to $80 \%$ confluence in $100 \mathrm{~mm}$ tissue culture plates and serum-starved overnight. Cells were preincubated with $5 \mu \mathrm{g} / \mathrm{ml}$ AMD3100 before stimulation with $20 \mathrm{ng} / \mathrm{ml}$ CXCL12 for $20 \mathrm{~min}$ in serum-free media. Cells were stimulated with $1 \mu \mathrm{g} / \mathrm{ml} \mathrm{LPA}$ in serum-free media for $20 \mathrm{~min}$ as a control. Cells were solublized in lysis buffer provided by the manufacturer and cleared by centrifugation. Cleared lysates were incubated with RBD-GST beads for $1 \mathrm{~h}$ at $4^{\circ} \mathrm{C}$ to bind RhoGTP. The beads were washed, eluted in SDS-sample buffer and size-separated using reducing SDS-PAGE. Proteins were electrophoretically transferred to PVDF (Immobilon-P, Millipore, Bedford, MA, USA) as detailed previously ${ }^{6,50}$ and analyzed by immunoblot with anti-RhoA monoclonal antibody.

\section{RhoGTP and F-actin Fluorescence Microscopy}

T84 or IEC-6 monolayers were wounded as described above and stimulated with $20 \mathrm{ng} / \mathrm{ml}$ CXCL12 or $1 \mu \mathrm{g} / \mathrm{ml} \mathrm{LPA}$ for $20 \mathrm{~min}$. The monolayers were fixed with $4 \%(\mathrm{w} / \mathrm{v})$ paraformaldehyde (Kodak Eastman Company, Rochester, NY, USA) in PBS for $15 \mathrm{~min}$. Cells were quenched with $50 \mathrm{mM}$ $\mathrm{NH}_{4} \mathrm{Cl}$ in PBS and permeablized with $0.3 \%(\mathrm{v} / \mathrm{v})$ Triton-X 100 in PBS for $10 \mathrm{~min}$. Cells were washed in $1 \%(\mathrm{w} / \mathrm{v}) \mathrm{BSA}$ in PBS wash buffer and blocked $30 \mathrm{~min}$ in $5 \%(\mathrm{w} / \mathrm{v})$ BSA/PBS and incubated with $40 \mu \mathrm{g} / \mathrm{ml} \mathrm{RBD-GST}$ or $40 \mu \mathrm{g} / \mathrm{ml}$ recombinant GST (Upstate, Charlottesville, VA, USA) overnight at $4{ }^{\circ} \mathrm{C}$. The cells were washed in buffer and incubated with $1 \mu \mathrm{g} / \mathrm{ml}$ mouse-anti-GST (Cell Signaling) or mouse IgG (Molecular Probes) in 1\% (w/v) BSA/PBS for $1 \mathrm{~h}$ at room temperature. Cells were washed and incubated with $2 \mu \mathrm{g} / \mathrm{ml}$ Alexafluor-488 goat-anti-mouse antibody (Molecular Probes). Cells were then stained for F-actin using Alexafluor595 phalloidin according to the manufacturer's directions. Cells were visualized using confocal or fluorescence microscopy. RhoGTP activity or F-actin accumulation in CXCL12stimulated or unstimulated control cells was quantified by measuring the fluorescence intensity along a line extending perpendicular from the wound edge into the epithelial monolayer using MetaMorph software. Fluorescence intensity for each line was plotted over distance from the wound edge and the length RhoGTP or F-actin localization defined as the distance from wound edge to baseline fluorescence. Three separate measurements along lines of equal length were performed for each wound in three separate experiments.

\section{F-actin Formation}

To quantify cellular F-actin content, IEC-6 were grown to $80 \%$ confluence and serum-starved $48 \mathrm{~h}$ before stimulation. To assess the specificity of binding CXCR4 cells were pretreated with $5 \mu \mathrm{g} / \mathrm{ml}$ AMD3100 overnight before stimulation with $20 \mathrm{ng} / \mathrm{ml}$ CXCL12. Cells were pretreated $30 \mathrm{~min}$ with the $10 \mu \mathrm{M}$ Y27632 to assess the involvement of ROCK in CXCR4mediated activation of F-actin. Cells were then permeablized with $1 \%(\mathrm{w} / \mathrm{v})$ saponin in PBS and stained with Alexafluor488-phalloidin for $20 \mathrm{~min}$ at $37^{\circ} \mathrm{C} 5 \% \mathrm{CO}_{2}$. To facilitate release of the cells from the dish $50 \mathrm{mM}$ EDTA in PBS was added and the cells were incubated at $37^{\circ} \mathrm{C}$ for $20 \mathrm{~min}$. The cells were gathered and transferred to FACS tubes (BD Biosciences, San Jose, CA, USA), washed in PBS, fixed in 2\% $(w / v)$ paraformaldehyde/PBS and fluorescence quantified by using an LSR2 flow cytometer (BD Biosciences).

\section{Immunoblot Analysis}

IEC-6 cells were grown to $80 \%$ confluence and serum-starved $48 \mathrm{~h}$ before stimulation with $20 \mathrm{ng} / \mathrm{ml}$ CXCL12. To assess if ROCK or MLCK was involved, cells were pretreated with $10 \mu \mathrm{M}$ Y27632 or $300 \mu \mathrm{M}$ Drev-PIK, respectively. Cells were solubilized in hypotonic lysis buffer $(50 \mathrm{mM}$ Tris- $\mathrm{HCl}, \mathrm{pH}$ 7.4, $10 \mathrm{mM} \mathrm{MgCl}_{2}$, and Protease Inhibitor Cocktail Set III (EMD CalBiochem)). Lysates were passed through a 25gauge needle and centrifuged at 550 r.p.m. in a benchtop centrifuge for $5 \mathrm{~min}$ at $4^{\circ} \mathrm{C}$ to pellet nuclei. Protein concentrations were determined using the Bradford protein assay kit (BCA kit, Pierce Biotechnology, Rockford, IL, USA) and $10 \mu \mathrm{g}$ of protein were size-separated using reducing SDSPAGE. Proteins were electrophoretically transferred to PVDF (Immobilon-P, Millipore) for immunoblot analysis as detailed previously. ${ }^{6,50}$ Equal protein loading was confirmed by Coomassie blue staining.

\section{Statistical Analysis}

Differences between unstimulated control and experimental samples were analyzed using an unpaired Student's $t$-test using SigmaStat (Jandel Scientific Software, San Rafael, CA, USA). Statistical significance was defined as $P \leq 0.05$.

\section{RESULTS \\ CXCL12-Induced Restitution Correlates with Accumulation of F-actin at the Leading Edge of Wounded IEC-6 Monolayers}

The cellular and biochemical mechanisms whereby extracellular immune mediators such as chemokines maintain and repair the innate epithelial barrier in inflammatory bowel disease, colorectal cancer, radiation injury, and infectious enterocolitis are not well understood. The objective of these studies was to therefore define the signaling mechanisms whereby the ubiquitous chemokine CXCL12 regulated epithelial sheet migration, an important step in barrier repair. ${ }^{3}$ As formation of actin filaments is an essential step in mucosal restitution, we first sought to determine if CXCL12 evoked 

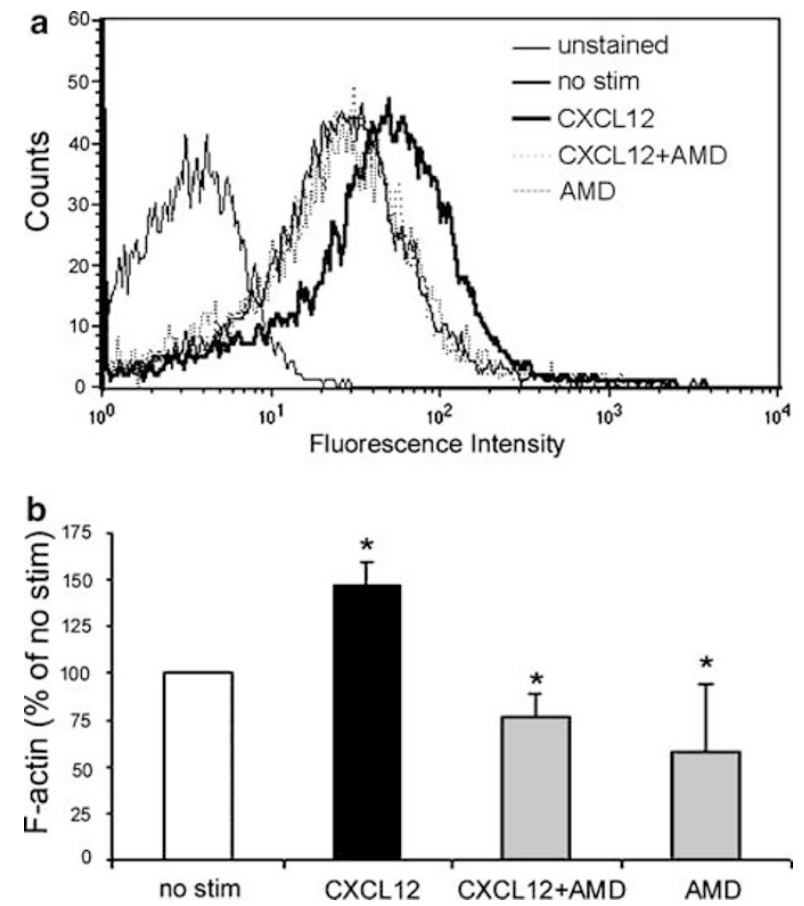

Figure 1 CXCL12 binding to CXCR4 increases F-actin accumulation. (a) Flow cytometric analyses of IEC-6 cells treated with $20 \mathrm{ng} / \mathrm{ml} \mathrm{CXCL12}$ (dark line) showed an increase in FITC-phalloidin staining representative of F-actin formation. Increased F-actin was inhibited upon treatment with $5 \mu \mathrm{g} / \mathrm{ml}$ of the specific CXCR4 antagonist AMD3100 (AMD; dotted line). Histogram data are representative of 3-5 experiments. (b) Quantification of F-actin as a percent of unstimulated IEC- 6 cells (\% no stim) indicated that AMD3100 completely blocked CXCL12-stimulated increases in F-actin. Cells were treated with AMD3100 alone as a control. Values are mean fluorescence intensity units normalized to untreated cells (no stim) for 3-5 independent experiments. Asterisks denote statistically significant difference $(P \leq 0.05)$ from untreated cells.

the accumulation of F-actin in intestinal cells. ${ }^{37,38,40}$ As shown in Figure 1, CXCL12-treated normal, non-transformed IEC- 6 cells had 50\% more F-actin than untreated cells when quantified using FITC-phalloidin staining in flow cytometric analyses. Further, increased F-actin was inhibited by treatment with the specific CXCR4 receptor antagonist AMD3100 before stimulation with CXCL12 (Figure $1 \mathrm{a}$ and $\mathrm{b}$ ).

Next, we assessed if CXCL12-induced F-actin accumulation corresponded with a change in localization within a migrating epithelial sheet consistent with its reorganization to the leading edge of wounded monolayers as a precursor to lamellae formation and restitution. ${ }^{37}$ To this end, a conventional intestinal wound healing model $^{51}$ was employed in which monolayers of IEC- 6 cells were wounded, stimulated with CXCL12, and F-actin visualized using FITC-phalloidin staining. In accordance with its observed accumulation, CXCL12 induced the localization of F-actin at the wound edge relative to unstimulated control cells (Figure 2a) and concomitantly simulated an increase in cell migration in those monolayers (Figure 2b). In parallel with our flow
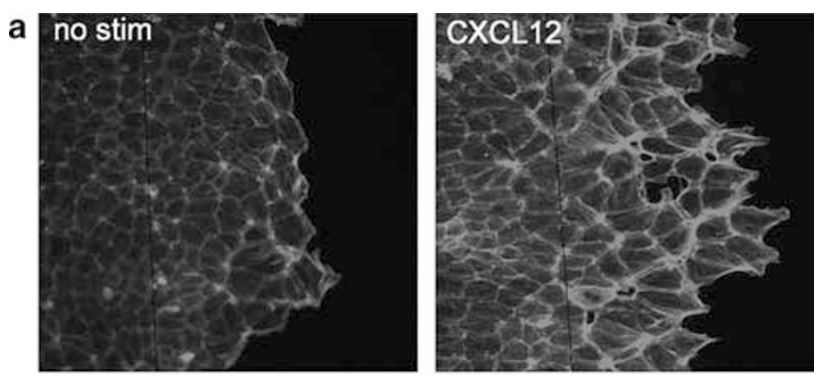

b

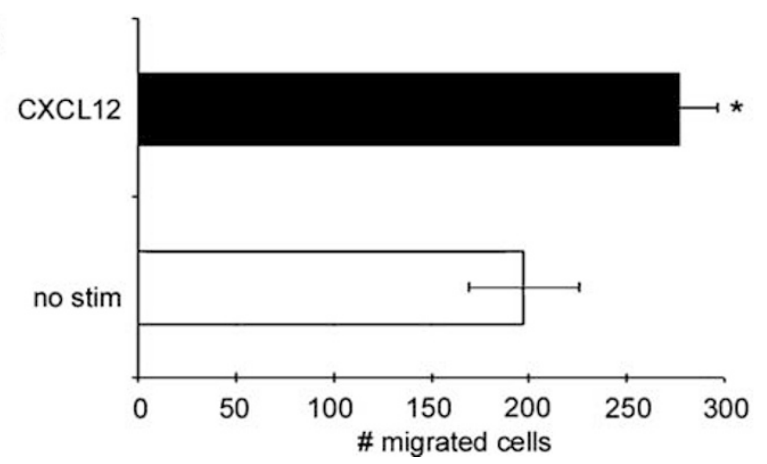

Figure 2 F-actin accumulation and distribution correlates to increased migration in CXCL12-treated epithelial cells. (a) FITC-phalloidin fluorescence microscopy of untreated (no stim) or CXCL12 $(20 \mathrm{ng} / \mathrm{ml})$-treated IEC-6 wounded monolayers indicated increased F-actin accumulation at the wound edge $20 \mathrm{~h}$ after chemokine stimulation. (b) Enumeration of migrating cells in CXCL12-treated and FITC-phalloidin stained monolayers. Data are representative of three independent experiments. Asterisk denotes statistically significant difference between CXCL12-stimulated and control monolayers $(P \leq 0.05)$.

cytometric analyses (Figure 1), additional experiments determined that inhibition of CXCR4 with AMD3100 abolished CXCL12-mediated restitution in IEC-6 cells (data not shown), thereby confirming that engagement to CXCR4 induced accumulation of F-actin at the leading edge of wounded IEC-6 monolayers.

\section{CXCR4 Signals RhoGTP in Intestinal Epithelial Cells}

As Rho acts as a molecular switch for a variety of cellular processes including F-actin cytoskeletal rearrangements, the formation of stress fibers, and restitutive enterocyte migration, ${ }^{39,52,53}$ we tested the hypothesis that CXCL12 binding to CXCR4 activates Rho in intestinal epithelial cells. RhotekinGST pull-down assays demonstrated the consistent increase in active RhoGTP in cells stimulated with CXCL12 (Figure 3a). Consistent with chemokine-induced F-actin accumulation AMD3100 abolished CXCL12-stimulated RhoGTP (Figure 3). Densitometry from three independent experiments confirmed the AMD3100-sensitive increase in RhoGTP formation (Figure 3b). Immunofluorescence analyses verified the increase in RhoGTP in CXCL12-stimulated cells, with the cellular distribution of active Rho in chemokine-stimulated cells (Figure 3c, top panels) paralleling its distribution in cells transfected with dominant-active RhoGFP (Figure 3c, middle panel). 
a

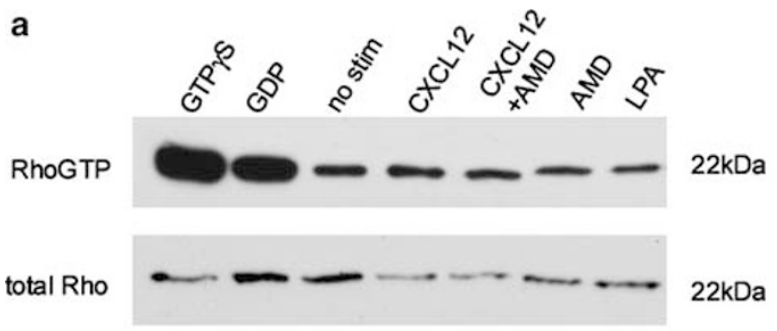

b

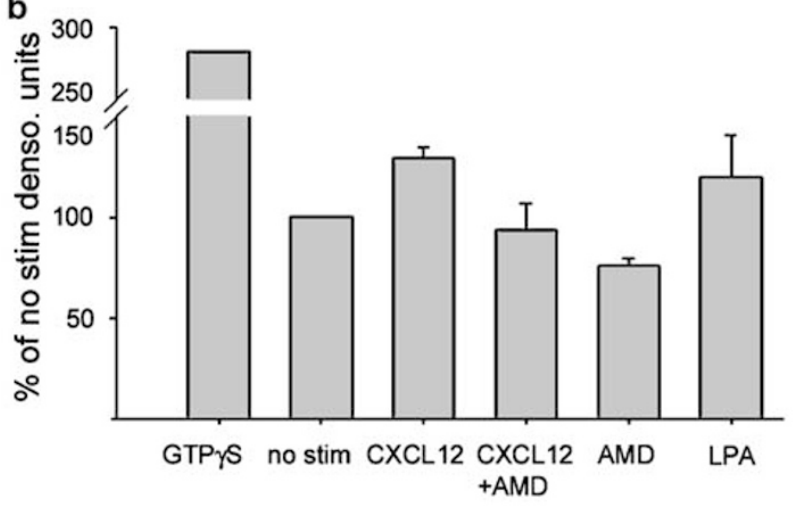

d

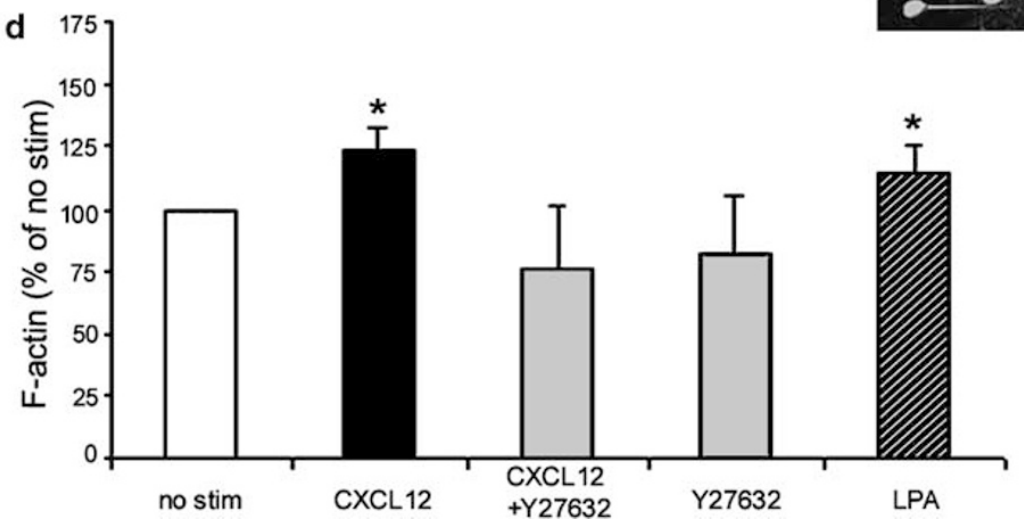

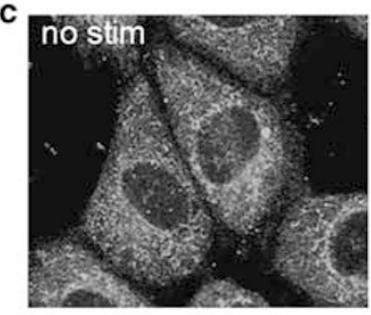
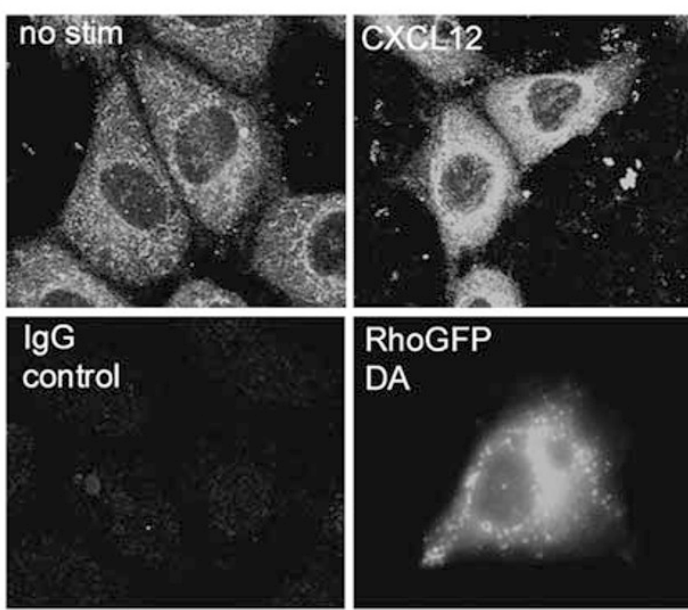

RhoGFP

DA
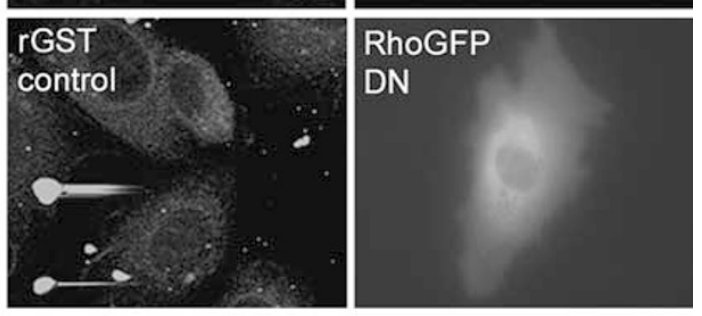

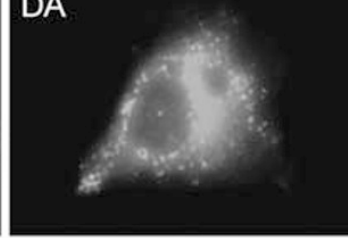

Figure 3 CXCR4 signals activation of Rho in IEC-6 cells. (a) RhoGTP pull-down assay with Rhotekin-GST and immunoblot analysis indicated an increase in

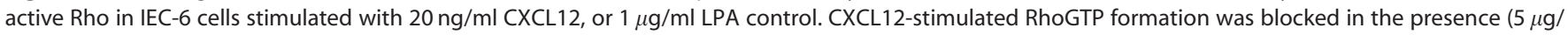
$\mathrm{ml}$ ) of the CXCR4 antagonist AMD3100 (AMD). Immunoblots of total Rho were assessed as a loading control. (b) Gel densitometry of active RhoGTP

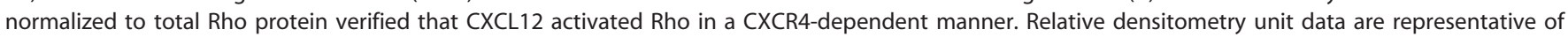
three independent experiments. (c) Confocal fluorescence microscopy of IEC-6 cells treated with $20 \mathrm{ng} / \mathrm{ml}$ CXCL12 confirmed increased active RhoGTP formation. CXCL12-stimulated RhoGTP immunoreactivity was similar to cells transfected with dominant-active (DA)-RhoGFP and distinct from that observed in dominant-negative (DN)-Rho transfectants or the rGST controls. (d) Flow cytometric analysis of IEC- 6 cells showed that the downstream Rho effector kinase (ROCK) contributes to CXCL12-mediated F-actin accumulation. CXCL12-stimulated cells were incubated with or without the ROCK inhibitor Y27632, permeablized and stained with FITC-phalloidin and analyzed by flow cytometry. IEC- 6 cells stimulated with LPA (1 $\mu$ g/ml) and Y27632 alone ( $10 \mu \mathrm{M})$ were analyzed as controls. Values are mean fluorescence intensity units normalized to untreated cells (no stim) for 3-5 independent experiments. Asterisks denote statistically significant difference from untreated cells $(P \leq 0.05)$.

Next, we asked if the Rho-kinase (ROCK), a major downstream effector of activated Rho known to stimulate F-actin formation and actinomyosin bundling, ${ }^{54,55}$ played a role in CXCL12-mediated F-actin accumulation. As shown in Figure 3d, the specific ROCK inhibitor Y27632 blocked CXCL12-mediated F-actin accumulation in IEC-6 (Figure 3d). Taken together these data show that CXCL12 binding to CXCR4 activates Rho in a model of normal intestinal epithelium and implicates involvement of the downstream RhoGTP effector ROCK in CXCL12-stimulated F-actin changes.

\section{CXCL12 Signaling Regulates MLC Phosphorylation through ROCK and MLCK in IEC-6 Cells}

MLC is a regulatory subunit of myosin that upon activation by phosphorylation facilitates the assembly of myosin and its interaction with F-actin to form contractile actomyosin fibers. ${ }^{5-56}$ MLCK is thought to be the major kinase responsible for phosphorylation of MLC in intestinal epithelial cells. ${ }^{41,57,58}$ In addition, ROCK can regulate MLC either by inactivating its regulatory phosphatase, myosin light chain phosphatase (MYPT1), or by directly phosphorylating MLC at serine 19 , its 

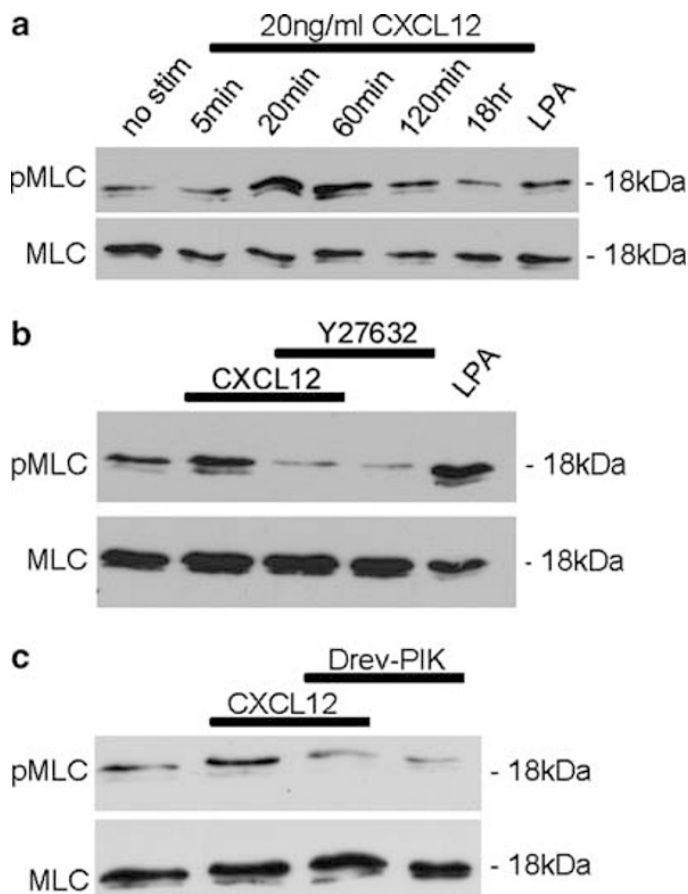

Figure 4 CXCL12 stimulates phosphorylation of MLC via ROCK and MLCK. (a) Immunoblot analysis of phospho-MLC (pMLC) and total MLC in IEC-6 cells stimulated with $20 \mathrm{ng} / \mathrm{ml} \mathrm{CXCL12}$ for $5,20,60,120 \mathrm{~min}$, or $18 \mathrm{~h}$ showed CXCL12 increased phosphorylation of MLC maximally at 20 and 60 min above unstimulated cells (no stim). (b and c) Inhibition of ROCK with Y27632 $(10 \mu \mathrm{M})$ or MLCK with Drev-PIK $(300 \mu \mathrm{M})$ abolished CXCL12mediated phosphorylation of MLC. Cells treated with Y27632 $(10 \mu \mathrm{M})$, or Drev-PIK $(300 \mu \mathrm{M})$ alone or with $1 \mu \mathrm{g} / \mathrm{ml}$ LPA were controls. Data are representative of three independent experiments.

primary phosphorylation site. ${ }^{54,59}$ We therefore asked whether CXCR4 regulated MLC phosphorylation. Immunoblot analysis of IEC-6 cells using an antibody specific for the phosphorylation of MLC serine 19 showed an increase in phospho-MLC (pMLC) in cells stimulated with CXCL12 for 20 and $60 \mathrm{~min}$ (Figure 4a). CXCL12 phosphorylation of pMLC is abrogated upon pretreatment with the specific ROCK inhibitor Y27632 (Figure $4 \mathrm{~b}$ ) or the MLCK inhibitor Drev-PIK (Figure 4c), ${ }^{45}$ demonstrating a role for those effector kinases in CXCL12 signaling. Further immunoblot analysis of the inactivating phosphate group showed that CXCL12 downmodulates MYPT1 thorough ROCK (data not shown). Together, these data indicate that CXCL12 activates MLC by increasing MLCK activity as well as negatively regulating the balancing phosphatase via ROCK signaling.

\section{ROCK and MLCK are Involved in CXCR4-Mediated Wound Healing of IEC-6 Monolayers}

ROCK and MLCK have been shown to work in concert to regulate MLC and actinomyosin bundling important in wound healing. ${ }^{41,60}$ Therefore, we next sought to determine if CXCR4 stimulated restitution through ROCK and MLCK. To this end, we performed wound healing assays in which separate IEC-6 monolayers were wounded and stimulated
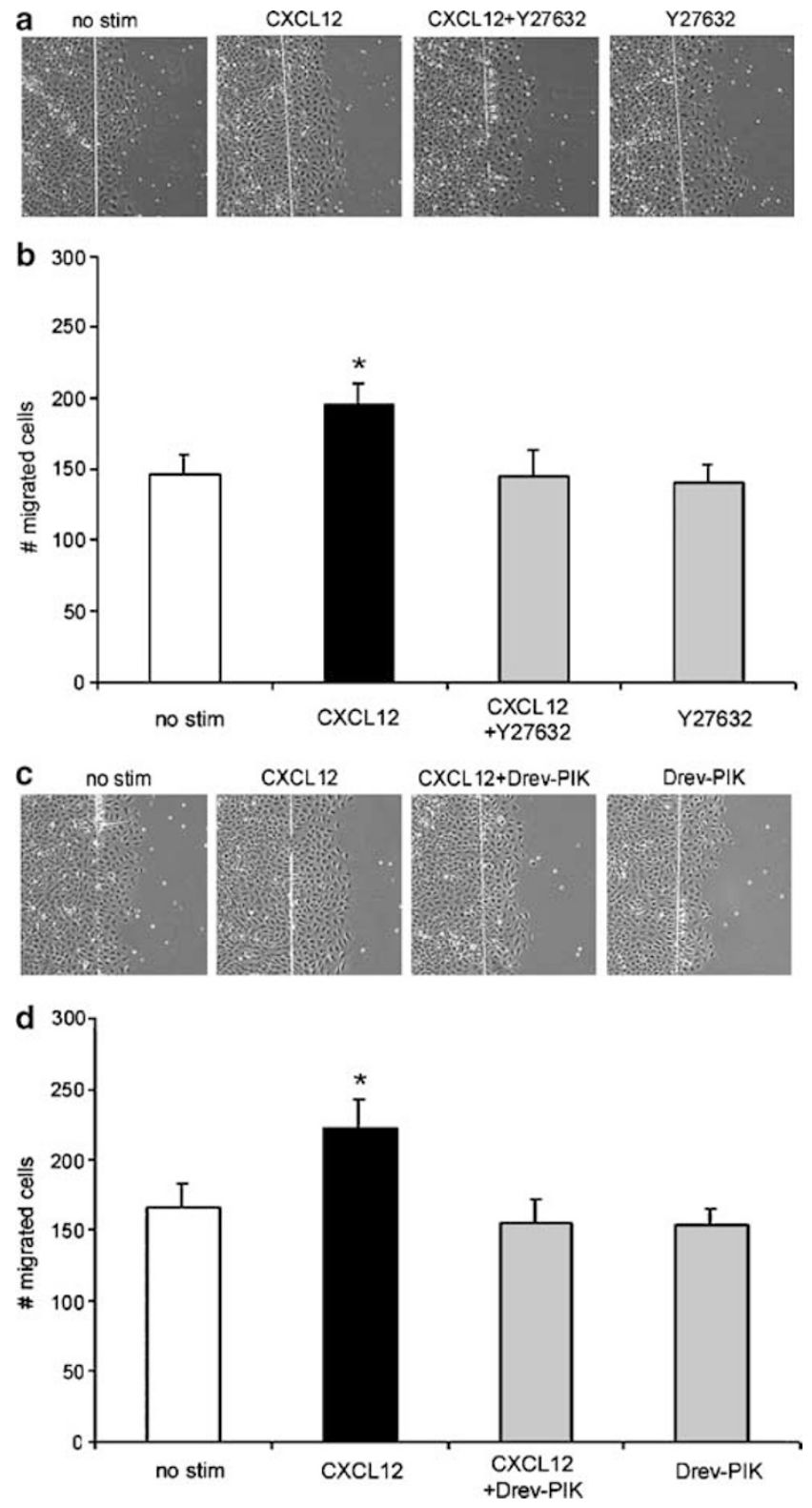

Figure 5 CXCL12-mediated restitution involves ROCK and MLCK. IEC-6 cells were wounded and restitution quantified by enumerating cells that migrated into the denuded ulcer in 3-5 fields of 2-3 wounds per experiment ( $n=3$ independent experiments). Wounded IEC- 6 monolayers treated with $20 \mathrm{ng} / \mathrm{ml} \mathrm{CXCL12} \mathrm{demonstrated} \mathrm{increased} \mathrm{restitution} \mathrm{relative}$ to unstimulated cells (no stim). Treatment with the ROCK inhibitor Y27632 $(10 \mu \mathrm{M})(\mathbf{a}$ and $\mathbf{b})$ or the MLCK inhibitor Drev-PIK $(300 \mu \mathrm{M})$ (c and d) impeded CXCL12 restitution. Asterisks denote statistically significant difference from unstimulated monolayers $(P \leq 0.05)$.

with $20 \mathrm{ng} / \mathrm{ml}$ CXCL12 or pretreated with ROCK inhibitor Y27632 (Figure 5a and b) or the MLCK inhibitor Drev-PIK (Figure $5 \mathrm{c}$ and $\mathrm{d}$ ). Untreated wounded monolayers were examined as a separate control. As we had shown previously, CXCL12 consistently increased the number of cells migrating across the wounded epithelial monolayer relative to untreated monolayers (Figure 5). Consistent with our hypothesis, we observed that inhibition of ROCK (Figure 5b) or, separately, 

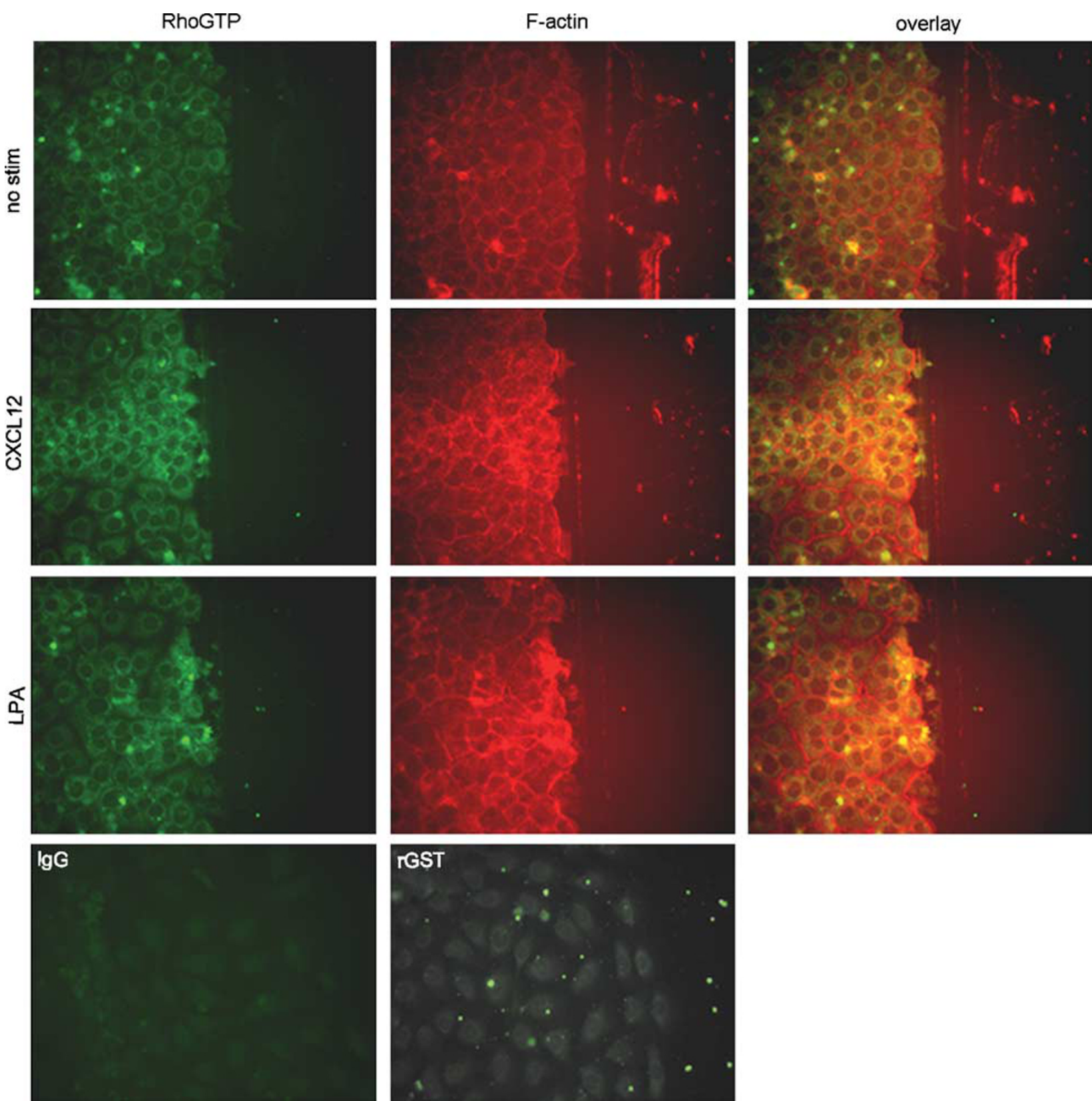

Figure 6 CXCL12 stimulates accumulation of F-actin and RhoGTP at the leading edge of migrating IEC- 6 epithelial sheets. IEC- 6 monolayers wounded with a razor blade were incubated $20 \mathrm{~min}$ with or without $20 \mathrm{ng} / \mathrm{ml} \mathrm{CXCL12,} \mathrm{or} 1 \mu \mathrm{g} / \mathrm{ml} \mathrm{LPA}$ as a control, fixed, permeablized, and stained for RhoGTP using Rhotekin-GST and an anti-GST antibody, or F-actin with Alexa-fluor-595-phalloidin. Photomicrographs indicated the CXCL12 stimulated accumulation of F-actin and RhoGTP at the leading edge of new wounds greater than that of unstimulated cells (no stim). Cells were examined using fluorescence microscopy at $\times 400$. Data are representative of three independent experiments.

MLCK (Figure 5d) significantly impeded CXCL12-mediated restitution.

\section{CXCL12 Stimulates Localization of F-actin and RhoGTP to the Leading Edge of IEC- 6 Wounds}

Since RhoGTP and F-actin are known to be present at the leading edge of wounded epithelial monolayers, ${ }^{37,40,41}$ we next determined if CXCL12 stimulated the accumulation of RhoGTP (Figure 6, left panels) and F-actin (Figure 6, middle panels) at the leading edge of wounded IEC-6 monolayers. The increase in active Rho and reorganization of F-actin in CXCL12 treated monolayers was greater than that seen in unstimulated cells (no stim) and paralleled that observed in the LPA-treated positive control epithelium (Figure 6). Together our data are consistent with the notion that the canonical wound-healing pathway consisting of RhoGTP, ROCK, MLCK, pMLC, and accumulation of F-actin is stimulated by CXCL12 in IEC-6 cells. 


\section{CXCL12 Increases Wound Healing in Polarized Human T84 Model Epithelium Using a Mechanism Analogous to that of IEC-6 Cells}

Polarized human T84 epithelial monolayers were next used to determine if CXCR4-mediated restitution was similarly regulated in a model of differentiated human intestinal epithelium. For these studies, we first established a wound healing assay using human intestinal T84 epithelial cells cultured on polycarbonate filters in which those cells are known to differentiate spontaneously into a polarized monolayer akin to the in vivo mucosa. ${ }^{28,46}$ Differentiated and polarized epithelial monolayers possessing TER $\geq 1000 \Omega \mathrm{cm}^{2}$ were reproducibly wounded (Figure 7). Wounded monolayers were left untreated (no stim) or were stimulated with CXCL12 and closure of those $\sim 0.8-1.0 \mathrm{~mm}$ circular wounds was monitored and wound closure calculated. As shown in Figure 7a, CXCL12 enhanced wound closure with a statistically significant increase in restitution observed from day 3 through day 6 of treatment. In parallel with our previous report that CXCL12 strengthens barrier integrity in non-wounded, differentiating model epithelia, ${ }^{28}$ the TER of wounded T84 monolayers was signi- ficantly higher in CXCL12-treated monolayers relative to the unstimulated controls (Figure 7a, bottom). In Figure 7b representative CXCL12-treated monolayer shown at day 3 of stimulation demonstrates that polarized monolayers treated with CXCL12 heal faster and approach complete closure relative to unstimulated T84 monolayers.

As a final step, we sought to determine if CXCL12 initiated wound closure in T84 model epithelia using similar mechanisms as defined for normal, non-transformed IEC-6 cells. Fluorescence microscopy confirmed that CXCL12-stimulated wound closure in polarized, differentiated monolayers was similarly associated with the accumulation of F-actin cables and RhoGTP at the leading edge after stimulation (Figure 7c). This accumulation, measured as the distance of fluorescence intensity from the wound edge, was statistically greater than that observed in unstimulated control cells (Figure 7c). Combined, these data demonstrate that CXCL12 stimulates the accumulation of F-actin and RhoGTP at the wound edge in two characteristic models of intestinal epithelium. Collectively, our data in the T84 human epithelial model are consistent with our biochemical and wound a
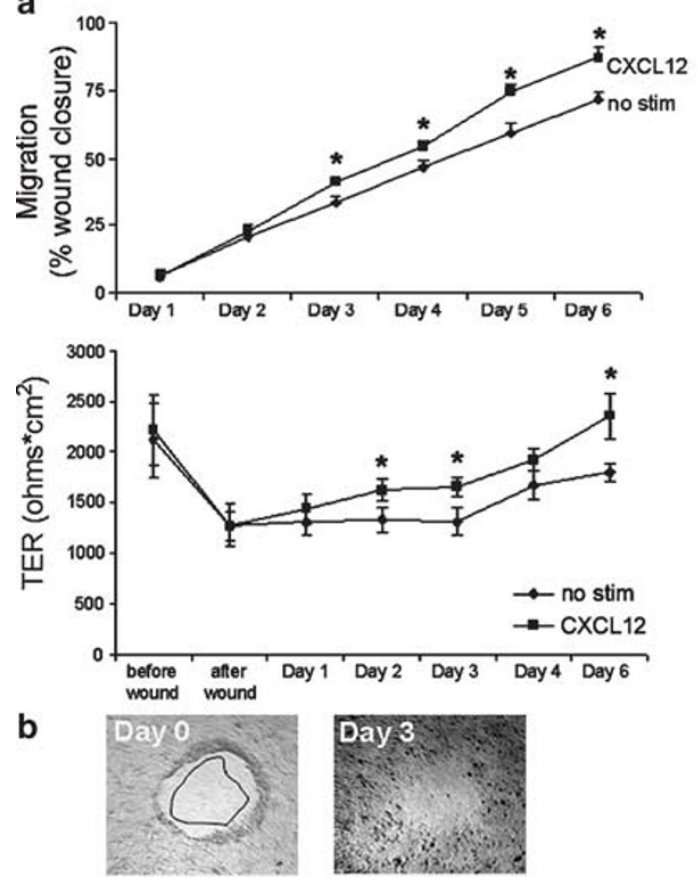

c
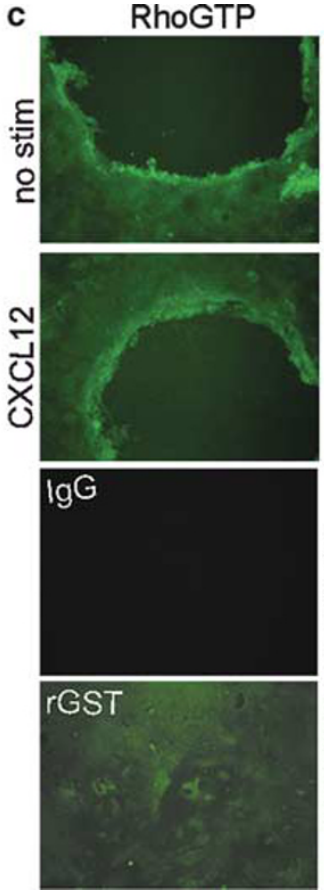

F-actin
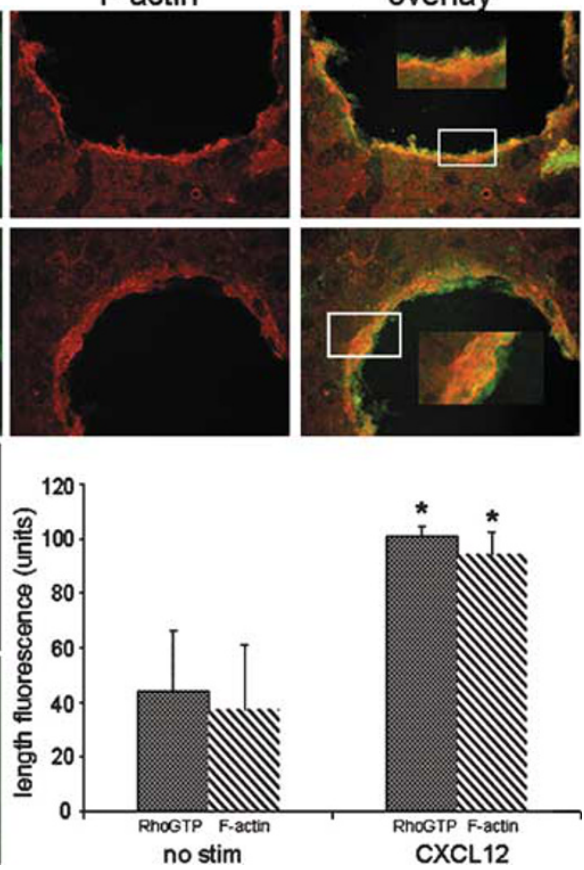

Figure 7 CXCL12 mediates wound closure and induces the accumulation of RhoGTP and F-actin in polarized human model epithelium. CXCL12-treated monolayers demonstrated increased closure and increased TER relative to untreated monolayers. (a, top panel) Wounded polarized T84 monolayers were stimulated with $20 \mathrm{ng} / \mathrm{ml} \mathrm{CXCL12}$ and photomicrographs taken directly after wounding $(\mathbf{b}, 0 \mathrm{~h})$ and daily after that for 4-6 days. Relative area of the wounds was calculated using MetaMorph software and wound closure (a, top) was monitored over time by normalizing wound area to $0 \mathrm{~h}$ and shown as a percentage of the initial wound area. (a, bottom panel) TER was measured on the same wounded T84 monolayers as measured in the top panel and demonstrated the parallel increase in barrier integrity with wound closure. (b) Representative T84 monolayer wounds at days 0 and 3 of CXCL12 treatment. Wound closure observed on day 3 outlined and superimposed upon the day 0 wound demonstrated the consistent restitution of CXCL12 treated T84 monolayers. Data are representative of 6-17 independent wounds. (c) Photomicrographs demonstrate the significantly increased accumulation of F-actin and RhoGTP at the leading edge of wounds in CXCL12-treated relative to unstimulated cells (no stim). The length of F-actin and RhoGTP fluorescence from the wound edge was quantified using MetaMorph software as described in Materials and Methods. Cells were examined using fluorescence microscopy at $\times 100$ (insets $\times 200$ ). Immunofluorescence data are representative of three independent monolayers. Values in (a and $\mathbf{c}$ ) are the mean \pm s.d. of three independent monolayers. Asterisks denote statistically significant difference from unstimulated (no stim) monolayers $(P \leq 0.05)$. 
healing data in IEC-6 cells and indicate that the essential chemokine CXCL12 and its receptor CXCR4 are likely candidate regulators of mucosal restitution in the human gastrointestinal mucosa.

\section{DISCUSSION}

Previous investigations indicate that RhoGTP activation leading to regulation of MLC, with the cooperation of ROCK and MLCK, results in actomyosin bundling and F-actin accumulation and epithelial sheet migration. Although these key effectors are known to regulate, in part, epithelial migration, the actual cellular and biochemical mechanisms whereby extracellular immune mediators regulate those constituents to maintain and repair the innate epithelial barrier are not well understood. ${ }^{37-39}$ Further, while the chemokine receptor CXCR4 has been shown to participate in epithelial sheet migration in embryonic development, ${ }^{4,61}$ the cellular mechanisms regulating those processes have yet to be elucidated. Our data describe for the first time the cellular signaling mechanism for CXCR4-facilitated sheet migration in model epithelium and establish the CXCR4-CXCL12 signaling axis as a novel extracellular activator of the canonical wound healing pathway. Epithelial restitution of model epithelia, together with our previous reports demonstrating a role for CXCR4-CXCL12 signaling in epithelial chemotaxis ${ }^{28}$ and metastasis ${ }^{20}$ of individual colonic carcinoma cells in vivo, implicate this chemokine receptor-chemokine ligand pair in the health and homeostasis of the intestinal barrier.

Migratory processes of single cells have been well studied (reviewed in Sheetz et $a l^{62}$ ) and are consistent with other reports showing that in leukocytes RhoGTPase regulates CXCR4-mediated chemotaxis or metastasis to sites of CXCL12 production. ${ }^{42,44}$ Our data demonstrate for the first time that CXCR4 signals RhoGTP in model intestinal epithelial cells and expand upon those reports by demonstrating CXCR4-mediated activation of Rho localization at the leading edge of migrating IEC-6 epithelial sheets. ${ }^{41,63}$ Recapitulation of these data in human polarized T84 monolayers demonstrates RhoGTP localization to the leading edge is not an artifact of either the rat IEC-6 cell line or the straight edge scrape wound. Since RhoGTP is known to be required for membrane protrusions in intestinal cell lines, ${ }^{64}$ we postulate CXCR4-mediated activation and localization of Rho at the leading edge of restitutive epithelial cells may facilitate formation of lamellae required for wound healing. As CXCR4 signaling is multifactorial and this receptor can signal through other GTPases such as Rac, ${ }^{65}$ we acknowledge that additional RhoGTPases, or down stream actin regulatory factors may also participate in CXCR4-mediated epithelial restitution.

Utilization of the pharmacological inhibitors Y27623 and Drev-PIK indicate that ROCK and MLCK are involved in CXCR4-mediated wound healing. ROCK is a well-characterized downstream effector of RhoGTP known to facilitate actomyosin bundling and contraction via phosphorylation of
MLC, either directly or indirectly by inhibiting MYPT1. ${ }^{54}$ MLCK is the major kinase responsible for phosphorylation of MLC in intestinal cells ${ }^{41,57}$ and works in conjunction with MYPT1 to regulate activation of MLC. We determined that CXCL12 leads to MLC phosphorylation in IEC-6 cells and show that inhibition of either ROCK or MLCK abolished CXCR4-mediated wound healing to control levels. Our data are consistent with the notion that CXCL12 stimulates MLC phosphorylation via ROCK and MLCK, which, in turn, promotes restitution by facilitating accumulation of F-actin.

Studies using the specific CXCR4 inhibitor AMD3100 showed that CXCR4 stimulates actin polymerization in IEC-6 cells. This increase in F-actin accumulation at the wound edge of IEC- 6 and T84 cells correlates with increased cell migration and parallels previous data showing F-actin rearrangement to the leading edge a hallmark event in epithelial wound healing. ${ }^{37,40,66}$ CXCL12-mediated accumulation of F-actin is activated after $20 \mathrm{~min}$ and parallels the activation of RhoGTP and pMLC. However, we also observed significant F-actin accumulation in CXCL12-stimulated monolayers $18 \mathrm{~h}$ after chemokine addition, a time point at which we show CXCL12 no longer activates pMLC suggesting that CXCR4-mediated F-actin accumulation may be regulated by more than one mechanism. For example, in leukocytes CXCR4 signals F-actin accumulation and migration via the LIM-kinase pathway, ${ }^{65}$ suggesting that LIMK and in turn cofilin-mediated inhibition of F-actin depolymerization ${ }^{67}$ may also regulate chemokine-mediated epithelial restitution.

Inflammatory bowel diseases such as Crohn's disease and ulcerative colitis, radiation injury and enterocolitis have long been associated with epithelial permeability defects. ${ }^{6-70}$ Furthermore, mucosal healing is thought to be a major defect for people undergoing steroidal treatment for inflammatory bowel disease. ${ }^{71}$ The epithelium must be able to heal wounds rapidly that constantly afflict the intestine to prevent permeability defects and maintain health of this important innate immune barrier. Therefore, factors that contribute to wound healing are of clinical importance as possible therapeutics for permeability homeostasis. An array of cytokines and a subset of particular chemokines are upregulated during and participate in immunocyte infiltration into the gut mucosa. ${ }^{32,33,72}$ Notably an array of inflammatory chemokines including CXCL8, CCL2, and CCL5 are elevated in Crohn's disease and ulcerative colitis and likely direct the trafficking of monocytes and $\mathrm{T}$ lymphocytes into the gut mucosa. ${ }^{29-34}$ Mice deficient in the chemokine receptors CCR $5,{ }^{73}$ one of the receptors for CCL5, or alternatively, concomitant blockade of the chemokine receptors CCR2, receptor for CCL2, CCR5 and CXCR3 confers mucosal protection in dextran sodium sulfate-induced murine colitis through abrogation of leukocyte trafficking to the gut mucosa. ${ }^{36}$ Moreover, a recent report implicates gut $\mathrm{T}$ lymphocytes in exacerbating epithelial barrier defects and worsening gut inflammation in a murine model of colitis. ${ }^{74,75}$ Those reports ascribe a role for chemokines limited to the directed infiltration of the 
damage-provoking or, alternatively damage-exacerbating, immune cells into the gut mucosa in inflammatory bowel disease. However, our data endorse expanding that model and suggest a role for the immune surveillance chemokine and chemokine receptor pair CXCL12 and CXCR4 in the mucosal restitution steps subsequent to inflammatory injury.

\section{ACKNOWLEDGEMENT}

We thank Dr Joseph Barbieri, Medical College of Wisconsin, for the plasmid encoding dominant-negative Rho. This work was funded by NIDDK DK062066 and a FIRST Award from the Crohn's and Colitis Foundation of America.

1. Booth C, Brady G, Potten CS. Crowd control in the crypt. Nat Med 2002;8:1360-1361.

2. Mammen JM, Matthews JB. Mucosal repair in the gastrointestinal tract. Crit Care Med 2003;31:S532-S537.

3. Dignass AU. Mechanisms and modulation of intestinal epithelial repair. Inflamm Bowel Dis 2001;7:68-77.

4. Jacinto A, Martinez-Arias A, Martin P. Mechanisms of epithelial fusion and repair. Nat Cell Biol 2001;3:E117-E123.

5. Zlotnik A, Yoshie O. Chemokines: a new classification system and their role in immunity. Immunity 2000;12:121-127.

6. Dwinell MB, Ogawa $H$, Barrett $K E$, et al. SDF-1/CXCL12 regulates CAMP production and ion transport in intestinal epithelial cells via CXCR4. Am J Physiol Gastrointest Liver Physiol 2004;286:G844-G850.

7. Dwinell MB, Eckmann L, Leopard JD, et al. Chemokine receptor expression by human intestinal epithelial cells. Gastroenterology 1999;117:359-367.

8. Jordan NJ, Kolios G, Abbot SE, et al. Expression of functional CXCR4 chemokine receptors on human colonic epithelial cells. J Clin Invest 1999;104:1061-1069.

9. Izadpanah A, Dwinell MB, Eckmann L, et al. Regulated MIP-3alpha/ CCL20 production by human intestinal epithelium: mechanism for modulating mucosal immunity. Am J Physiol Gastrointest Liver Physiol 2001;280:G710-G719.

10. Brand S, Sakaguchi T, Gu X, et al. Fractalkine-mediated signals regulate cell-survival and immune-modulatory responses in intestinal epithelial cells. Gastroenterology 2002;122:166-177.

11. Tachibana $K$, Hirota $S$, lizasa $H$, et al. The chemokine receptor CXCR4 is essential for vascularization of the gastrointestinal tract. Nature 1998;393:591-594.

12. Amara A, Gall SL, Schwartz O, et al. HIV coreceptor downregulation as antiviral principle: SDF-1alpha-dependent internalization of the chemokine receptor CXCR4 contributes to inhibition of HIV replication. J Exp Med 1997;186:139-146.

13. Poznansky MC, Olszak IT, Foxall $R$, et al. Active movement of $T$ cells away from a chemokine. Nat Med 2000;6:543-548.

14. Lataillade JJ, Clay D, Bourin $P$, et al. Stromal cell-derived factor 1 regulates primitive hematopoiesis by suppressing apoptosis and by promoting $\mathrm{G}(0) / \mathrm{G}(1)$ transition in CD34(+) cells: evidence for an autocrine/paracrine mechanism. Blood 2002;99:1117-1129.

15. Marchesi F, Monti $\mathrm{P}$, Leone $\mathrm{BE}$, et al. Increased survival, proliferation, and migration in metastatic human pancreatic tumor cells expressing functional CXCR4. Cancer Res 2004;64:8420-8427.

16. Muller A, Homey B, Soto $\mathrm{H}$, et al. Involvement of chemokine receptors in breast cancer metastasis. Nature 2001;410:50-56.

17. Phillips RJ, Burdick MD, Lutz M, et al. The stromal derived factor-1/ CXCL12-CXC chemokine receptor 4 biological axis in non-small cell lung cancer metastases. Am J Respir Crit Care Med 2003;167: 1676-1686.

18. Schrader AJ, Lechner $\mathrm{O}$, Templin $\mathrm{M}$, et al. CXCR4/CXCL12 expression and signalling in kidney cancer. Br J Cancer 2002;86:1250-1256.

19. Scotton CJ, Wilson JL, Milliken D, et al. Epithelial cancer cell migration: a role for chemokine receptors? Cancer Res 2001;61:4961-4965.

20. Wendt MK, Johanesen PA, Kang-Decker N, et al. Silencing of epithelial CXCL12 expression by DNA hypermethylation promotes colonic carcinoma metastasis. Oncogene 2006;25:4986-4997.
21. Kryczek I, Wei S, Keller E, et al. Stromal derived factor (SDF-1/CXCL12) and human tumor pathogenesis. Am J Physiol Cell Physiol 2006;292:C987-C995.

22. Luo C, Pan H, Mines M, et al. CXCL12 induces tyrosine phosphorylation of cortactin, which plays a role in CXC chemokine receptor 4-mediated extracellular signal-regulated kinase activation and chemotaxis. J Biol Chem 2006;281:30081-30093.

23. Engl T, Relja B, Marian D, et al. CXCR4 chemokine receptor mediates prostate tumor cell adhesion through alpha5 and beta3 integrins. Neoplasia 2006;8:290-301.

24. Christ M, McCartney-Francis NL, Kulkarni $A B$, et al. Immune dysregulation in TGF-beta 1-deficient mice. J Immunol 1994;153: 1936-1946.

25. Durbin JE, Hackenmiller R, Simon MC, et al. Targeted disruption of the mouse Stat 1 gene results in compromised innate immunity to viral disease. Cell 1996;84:443-450.

26. Ishikawa H, Carrasco D, Claudio E, et al. Gastric hyperplasia and increased proliferative responses of lymphocytes in mice lacking the $\mathrm{COOH}$-terminal ankyrin domain of NF-kappaB2. J Exp Med 1997;186:999-1014.

27. Sibilia M, Wagner EF. Strain-dependent epithelial defects in mice lacking the EGF receptor. Science 1995;269:234-238.

28. Smith JM, Johanesen PA, Wendt MK, et al. CXCL12 activation of CXCR4 regulates mucosal host defense through stimulation of epithelial cell migration and promotion of intestinal barrier integrity. Am J Physiol Gastrointest Liver Physiol 2005;288:G316-G326.

29. Reinecker HC, Loh EY, Ringler DJ, et al. Monocyte-chemoattractant protein 1 gene expression in intestinal epithelial cells and inflammatory bowel disease mucosa. Gastroenterology 1995; 108:40-50.

30. Mazzucchelli L, Hauser C, Zgraggen K, et al. Differential in situ expression of the genes encoding the chemokines MCP-1 and RANTES in human inflammatory bowel disease. J Pathol 1996;178:201-206.

31. Ina K, Kusugami K, Yamaguchi T, et al. Mucosal interleukin-8 is involved in neutrophil migration and binding to extracellular matrix in inflammatory bowel disease. Am J Gastroenterol 1997;92: 1342-1346.

32. MacDermott RP, Sanderson IR, Reinecker HC. The central role of chemokines (chemotactic cytokines) in the immunopathogenesis of ulcerative colitis and Crohn's disease. Inflamm Bowel Dis 1998;4:54-67.

33. Papadakis KA, Targan SR. The role of chemokines and chemokine receptors in mucosal inflammation. Inflamm Bowel Dis 2000;6: 303-313.

34. Banks C, Bateman A, Payne R, et al. Chemokine expression in IBD. Mucosal chemokine expression is unselectively increased in both ulcerative colitis and Crohn's disease. J Pathol 2003;199:28-35.

35. Anders HJ, Frink $M$, Linde $Y$, et al. CC chemokine ligand 5/RANTES chemokine antagonists aggravate glomerulonephritis despite reduction of glomerular leukocyte infiltration. J Immunol 2003;170:5658-5666.

36. Tokuyama $\mathrm{H}$, Ueha $\mathrm{S}$, Kurachi $\mathrm{M}$, et al. The simultaneous blockade of chemokine receptors CCR2, CCR5 and CXCR3 by a non-peptide chemokine receptor antagonist protects mice from dextran sodium sulfate-mediated colitis. Int Immunol 2005;17:1023-1034.

37. Nusrat A, Delp C, Madara JL. Intestinal epithelial restitution. Characterization of a cell culture model and mapping of cytoskeletal elements in migrating cells. J Clin Invest 1992;89:1501-1511.

38. Nusrat A, Parkos CA, Liang TW, et al. Neutrophil migration across model intestinal epithelia: monolayer disruption and subsequent events in epithelial repair. Gastroenterology 1997;113:1489-1500.

39. Santos MF, McCormack SA, Guo Z, et al. Rho proteins play a critical role in cell migration during the early phase of mucosal restitution. J Clin Invest 1997:100:216-225.

40. Lotz MM, Rabinovitz I, Mercurio AM. Intestinal restitution: progression of actin cytoskeleton rearrangements and integrin function in a model of epithelial wound healing. Am J Pathol 2000;156:985-996.

41. Russo JM, Florian $\mathrm{P}$, Shen $\mathrm{L}$, et al. Distinct temporal-spatial roles for rho kinase and myosin light chain kinase in epithelial purse-string wound closure. Gastroenterology 2005;128:987-1001.

42. Vicente-Manzanares M, Cabrero JR, Rey M, et al. A role for the Rhop160 Rho coiled-coil kinase axis in the chemokine stromal cell-derived factor-1alpha-induced lymphocyte actomyosin and microtubular organization and chemotaxis. J Immunol 2002;168:400-410. 
43. Zhao M, Discipio RG, Wimmer AG, et al. Regulation of CXCR4-mediated nuclear translocation of extracellular signal-related kinases 1 and 2 . Mol Pharmacol 2006;69:66-75.

44. Tan W, Martin D, Gutkind JS. The Ga13-Rho signaling axis is required for SDF-1 induced migration through CXCR4. J Biol Chem 2006;281:39542-39549.

45. Owens SE, Graham WV, Siccardi D, et al. A strategy to identify stable membrane-permeant peptide inhibitors of myosin light chain kinase. Pharm Res 2005;22:703-709.

46. Dharmsathaphorn K, McRoberts JA, Mandel KG, et al. A human colonic tumor cell line that maintains vectorial electrolyte transport. Am J Physiol 1984;246:G204-G208.

47. Hines OJ, Ryder N, Chu J, et al. Lysophosphatidic acid stimulates intestinal restitution via cytoskeletal activation and remodeling. J Surg Res 2000;92:23-28.

48. Dignass A, Lynch-Devaney K, Kindon $\mathrm{H}$, et al. Trefoil peptides promote epithelial migration through a transforming growth factor betaindependent pathway. J Clin Invest 1994;94:376-383.

49. Ren XD, Kiosses WB, Schwartz MA. Regulation of the small GTP-binding protein Rho by cell adhesion and the cytoskeleton. EMBO J 1999;18:578-585.

50. Heidemann J, Ogawa $\mathrm{H}$, Rafiee $\mathrm{P}$, et al. Mucosal angiogenesis regulation by CXCR4 and its ligand CXCL12 expressed by human intestinal microvascular endothelial cells. Am J Physiol Gastrointest Liver Physiol 2004;286:G1059-G1068.

51. McCormack SA, Viar MJ, Johnson LR. Migration of IEC- 6 cells: a mode for mucosal healing. Am J Physiol 1992;263:G426-G435.

52. Ridley AJ, Hall A. The small GTP-binding protein rho regulates the assembly of focal adhesions and actin stress fibers in response to growth factors. Cell 1992;70:389-399.

53. Brock J, Midwinter K, Lewis J, et al. Healing of incisional wounds in the embryonic chick wing bud: characterization of the actin purse-string and demonstration of a requirement for Rho activation. J Cell Biol 1996;135:1097-1107.

54. Kimura $K$, Ito $M$, Amano $M$, et al. Regulation of myosin phosphatase by Rho and Rho-associated kinase (Rho-kinase). Science 1996;273: 245-248.

55. Amano $M$, Ito $M$, Kimura $K$, et al. Phosphorylation and activation of myosin by Rho-associated kinase (Rho-kinase). J Biol Chem 1996;271:20246-20249.

56. Chen BH, Tzen JT, Bresnick AR, et al. Roles of Rho-associated kinase and myosin light chain kinase in morphological and migratory defects of focal adhesion kinase-null cells. J Biol Chem 2002;277: 33857-33863.

57. Clayburgh DR, Rosen S, Witkowski ED, et al. A differentiationdependent splice variant of myosin light chain kinase, MLCK1, regulates epithelial tight junction permeability. J Biol Chem 2004;279:55506-55513.

58. Turner JR, Angle JM, Black ED, et al. PKC-dependent regulation of transepithelial resistance: roles of MLC and MLC kinase. Am J Physiol 1999;277:C554-C562.
59. Ikebe M, Hartshorne DJ. Phosphorylation of smooth muscle myosin at two distinct sites by myosin light chain kinase. J Biol Chem 1985;260:10027-10031.

60. Totsukawa G, Yamakita Y, Yamashiro S, et al. Distinct roles of ROCK (Rho-kinase) and MLCK in spatial regulation of MLC phosphorylation for assembly of stress fibers and focal adhesions in $3 T 3$ fibroblasts. J Cell Biol 2000;150:797-806.

61. Haas $P$, Gilmour D. Chemokine signaling mediates self-organizing tissue migration in the zebrafish lateral line. Dev Cell 2006;10:673-680.

62. Sheetz MP, Felsenfeld DP, Galbraith CG. Cell migration: regulation of force on extracellular-matrix-integrin complexes. Trends Cell Biol 1998;8:51-54.

63. Pertz O, Hodgson L, Klemke RL, et al. Spatiotemporal dynamics of RhoA activity in migrating cells. Nature 2006;440:1069-1072.

64. O'Connor KL, Nguyen BK, Mercurio AM. RhoA function in lamellae formation and migration is regulated by the alpha6beta4 integrin and cAMP metabolism. J Cell Biol 2000;148:253-258.

65. Nishita M, Aizawa H, Mizuno K. Stromal cell-derived factor 1alpha activates LIM kinase 1 and induces cofilin phosphorylation for T-cell chemotaxis. Mol Cell Biol 2002;22:774-783.

66. Bement WM, Forscher P, Mooseker MS. A novel cytoskeletal structure involved in purse string wound closure and cell polarity maintenance. J Cell Biol 1993;121:565-578.

67. Maekawa M, Ishizaki T, Boku S, et al. Signaling from Rho to the actin cytoskeleton through protein kinases ROCK and LIM-kinase. Science 1999;285:895-898.

68. Katz KD, Hollander D, Vadheim CM, et al. Intestinal permeability in patients with Crohn's disease and their healthy relatives. Gastroenterology 1989;97:927-931.

69. Wyatt J, Vogelsang $\mathrm{H}$, Hubl W, et al. Intestinal permeability and the prediction of relapse in Crohn's disease. Lancet 1993;341:1437-1439.

70. Welcker K, Martin A, Kolle $P$, et al. Increased intestinal permeability in patients with inflammatory bowel disease. Eur J Med Res 2004; 9:456-460.

71. Rutgeerts PJ. An historical overview of the treatment of Crohn's disease: why do we need biological therapies? Rev Gastroenterol Disord 2004;4(Suppl 3):S3-S9.

72. Hanauer SB. Inflammatory bowel disease: epidemiology, pathogenesis, and therapeutic opportunities. Inflamm Bowel Dis 2006;12(Suppl 1): S3-S9.

73. Andres PG, Beck PL, Mizoguchi E, et al. Mice with a selective deletion of the CC chemokine receptors 5 or 2 are protected from dextran sodium sulfate-mediated colitis: lack of CC chemokine receptor 5 expression results in a NK1.1+ lymphocyte-associated Th2-type immune response in the intestine. J Immunol 2000;164:6303-6312.

74. Hyun JG, Lee G, Brown JB, et al. Anti-interferon-inducible chemokine, CXCL10, reduces colitis by impairing $T$ helper-1 induction and recruitment in mice. Inflamm Bowel Dis 2005;11:799-805.

75. Clayburgh DR, Musch MW, Leitges M, et al. Coordinated epithelial NHE3 inhibition and barrier dysfunction are required for TNF-mediated diarrhea in vivo. J Clin Invest 2006;116:2682-2694. 